\title{
Photoluminescence and Structural Characteristics of Eu-doped $\mathrm{ZnO}-\mathrm{Li}_{3} \mathrm{NbO}_{4}$
}

\author{
Meng-Hsi Huang, Te-Hua Fang, ${ }^{*}$ Ming-Hong Lin, Chia-Wei Chang, and Yu-Cheng Fan
}

Department of Mechanical Engineering, National Kaohsiung University of Science and Technology,

No. 415, Jiangong Rd., Sanmin Dist., Kaohsiung City 80778, Taiwan

(Received January 19, 2019; accepted December 23, 2019)

Keywords: luminescence properties, sol-gel method, emission intensity

In this study, $\mathrm{Eu}^{3+}$-doped $\mathrm{ZnO}-\mathrm{Li}_{3} \mathrm{NbO}_{4}$ phosphors were prepared by the sol-gel method. The physical and luminescence properties of the $\mathrm{Eu}^{3+}$-doped $\mathrm{ZnO}-\mathrm{Li}_{3} \mathrm{NbO}_{4}$ structure were characterized. The results show the crystallinity of the biphasic $\mathrm{ZnO}-\mathrm{Li}_{3} \mathrm{NbO}_{4}$ structure sintered at temperatures above $400{ }^{\circ} \mathrm{C}$. The main excitation and emission bands of the $\mathrm{Eu}^{3+}$ doped $\mathrm{ZnO}-\mathrm{Li}_{3} \mathrm{NbO}_{4}$ phosphors were $466 \mathrm{~nm}\left({ }^{7} \mathrm{~F}_{0} \rightarrow{ }^{5} \mathrm{D}_{2}\right)$ and $615 \mathrm{~nm}\left({ }^{5} \mathrm{D}_{0} \rightarrow{ }^{7} \mathrm{~F}_{2}\right)$, respectively. When the amount of $\mathrm{Eu}^{3+}$ was $5 \%$, the highest emission intensity was obtained at $595 \mathrm{~nm}\left({ }^{5} \mathrm{D}_{0} \rightarrow{ }^{7} \mathrm{~F}_{1}\right)$ and $615 \mathrm{~nm}\left({ }^{5} \mathrm{D}_{0} \rightarrow{ }^{7} \mathrm{~F}_{2}\right)$.

\section{Introduction}

Zinc oxide-lithium niobate $\left(\mathrm{ZnO}-\mathrm{Li}_{3} \mathrm{NbO}_{4}\right)$ has become a popular material for application in nonlinear optical and optoelectronic devices. ${ }^{(1,2)}$ The use of a biphasic ceramic material plays an important role in optical or biomedical applications. For example, Fariña et al. ${ }^{(3)}$ studied biphasic calcium phosphate ceramics for biomedical and implanted applications. Bernardeschi et al. ${ }^{(4)}$ studied granules of biphasic ceramics for the rehabilitation of canal walls.

Among rare-earth-doped materials, $\mathrm{Eu}^{3+}$ attracts considerable scientific attention. The intra-4f-shell transitions of $\mathrm{Eu}^{3+}$ show that the excited levels shift the lower energy levels of ${ }^{5} \mathrm{D}_{0} \rightarrow{ }^{7} \mathrm{~F}_{j}(j=1,2,3,4) .{ }^{(5,6)}$ The optical properties of $\mathrm{Eu}^{3+}: \mathrm{ZnO}$ nanophosphors are important in material applications such as the fabrication of electroluminescence devices and biolabels. ${ }^{(7)}$ Ningthoujam et al. studied $\mathrm{ZnO}$ nanoparticles with and without $\mathrm{Li}^{+}$and $\mathrm{Eu}^{3+}$ ions at low temperatures and their luminescence properties. ${ }^{(7)}$ Red luminescence was observed in the wavelength range of $610-620 \mathrm{~nm}{ }^{(8,9)} \mathrm{ZnO}-\mathrm{Li}_{3} \mathrm{NbO}_{4}$ crystals exhibit a second phase structure and could be used as a capacity rare-earth-doped host material. However, there are only a few reports on the structure and luminescence of $\mathrm{ZnO}-\mathrm{Li}_{3} \mathrm{NbO}_{4}$ prepared by the sol-gel method.

In the present study, we synthesized $\mathrm{Eu}^{3+}$-doped $\mathrm{ZnO}-\mathrm{Li}_{3} \mathrm{NbO}_{4}$ by the sol-gel method and examined its structural, optical absorption, and photoluminescence properties.

*Corresponding author: e-mail: fang@nkust.edu.tw https://doi.org/10.18494/SAM.2020.2595 


\section{Experiments}

$\mathrm{ZnO}-\mathrm{Li}_{3} \mathrm{NbO}_{4}: \mathrm{Eu}$ powders were prepared by the sol-gel method. $99 \%$ zinc nitrate $\mathrm{Zn}\left(\mathrm{NO}_{3}\right)_{2}, 97.7 \%$ lithium nitrate $\left(\mathrm{LiNO}_{3}\right)$, niobium ethoxide $\mathrm{Nb}\left(\mathrm{OC}_{2} \mathrm{H}_{5}\right)_{5}$, and $99.8 \%$ citric acid (CA) were used as starting materials. First, stoichiometric amounts of $\mathrm{Zn}\left(\mathrm{NO}_{3}\right)_{2}, \mathrm{LiNO}_{3}$, $\mathrm{Nb}\left(\mathrm{OC}_{2} \mathrm{H}_{5}\right)_{5}$, europium nitrate pentahydrate $\left(\mathrm{Eu}\left(\mathrm{NO}_{3}\right)_{3} \cdot 5 \mathrm{H}_{2} \mathrm{O}\right)$, and $\mathrm{CA}$ were dissolved in distilled (D.I.) water. ${ }^{(10)}$ The precursor was dried in an oven at $150{ }^{\circ} \mathrm{C}$ for $2 \mathrm{~h}$. Then, the samples were placed in an $\mathrm{Al}_{2} \mathrm{O}_{3}$ crucible and then sintered in a furnace at $400-900{ }^{\circ} \mathrm{C}$.

The crystallinity of the samples was measured by X-ray diffraction (XRD, Rigaku D-max/IIB). The microstructure and selected-area electron diffraction (SAED) were characterized by ultrahigh-resolution analytical electron microscopy (HR-AEM, JEOL JEM2100F CS-STEM). Absorption spectra were obtained using a UV-Vis spectrometer (Jasco V-670 spectrophotometer). The Commission internationale de l'éclairage (CIE) spectrum obtained was analyzed using a photoluminescence (PL, Hitachi F-7000) spectrometer at room temperature.

\section{Results and Discussion}

Figure 1(a) shows the XRD patterns of $\mathrm{ZnO}-\mathrm{Li}_{3} \mathrm{NbO}_{4}$ synthesized at different sintering temperatures. The crystalline $\mathrm{ZnO}-\mathrm{Li}_{3} \mathrm{NbO}_{4}$ structure was formed gradually over $400{ }^{\circ} \mathrm{C}(\mathrm{ZnO}$, JCPDS Card No. 89-0510, unit cell parameters: $a, b=3.249 \AA$ and $c=5.206 \AA$, and $\mathrm{Li}_{3} \mathrm{NbO}_{4}$, JCPDS Card No. 75-0907, unit cell parameters: $a, b, c=8.429 \AA$ ). The main diffraction peak of $36.26^{\circ}(101)$ appeared at different synthesis temperatures. The diffraction peak intensity of $\mathrm{ZnO}-\mathrm{Li}_{3} \mathrm{NbO}_{4}$ with a biphasic polycrystalline structure increased with annealing temperature.

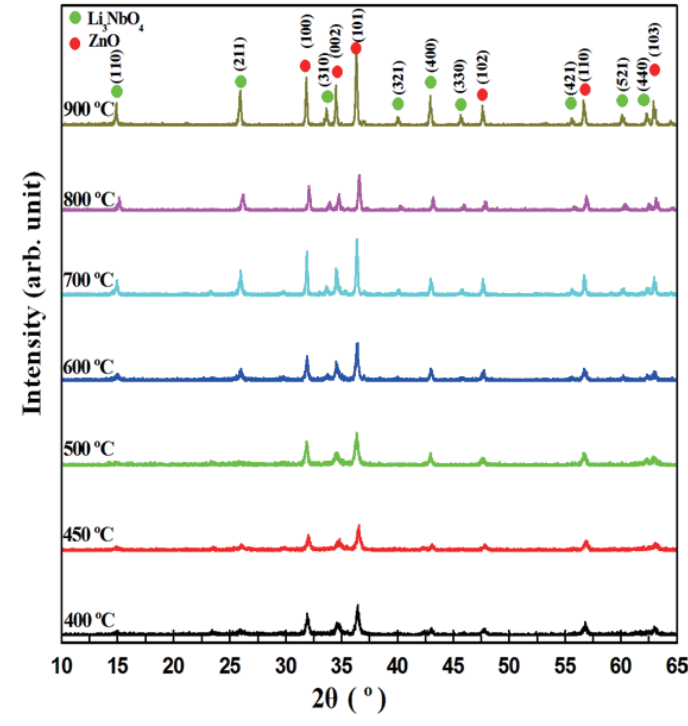

(a)

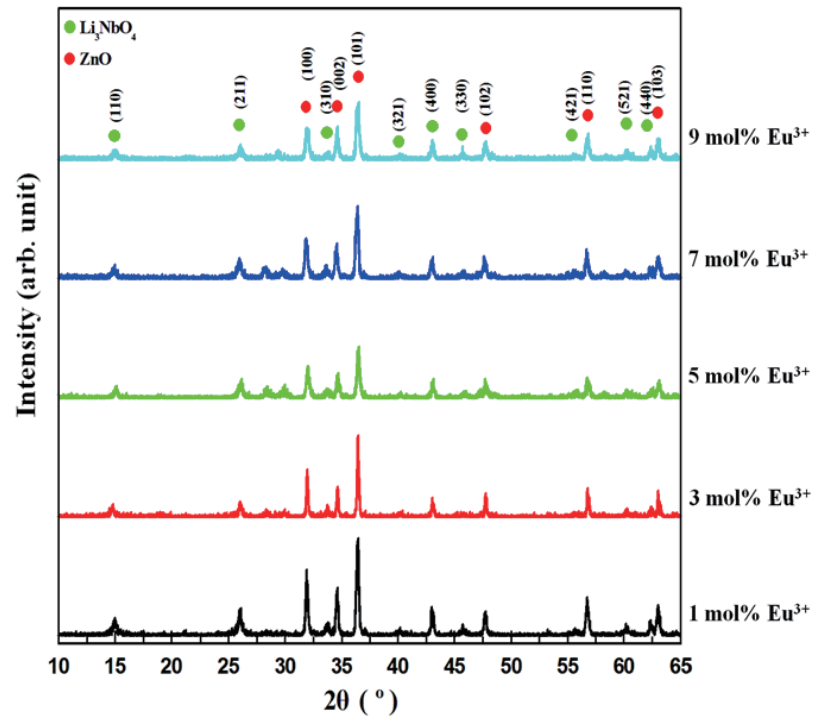

(b)

Fig. 1. (Color online) XRD patterns of $\mathrm{ZnO}-\mathrm{Li}_{3} \mathrm{NbO}_{4}$ synthesized at different (a) sintering temperatures and (b) $\mathrm{Eu}^{3+}$ concentrations. 
Figure 1(b) shows the XRD patterns of $\mathrm{Eu}^{3+}$-doped $\mathrm{ZnO}-\mathrm{Li}_{3} \mathrm{NbO}_{4}$, whose polycrystalline structure did not change. With increasing $\mathrm{Eu}^{3+}$ dopant concentration, the amount of $\mathrm{ZnO}-$ $\mathrm{Li}_{3} \mathrm{NbO}_{4}$ remained the same, which implies that $\mathrm{Eu}^{3+}$ can be integrated with a $\mathrm{ZnO}-\mathrm{Li}_{3} \mathrm{NbO}_{4}$ crystal. As the concentration of $\mathrm{Eu}^{3+}$ increases above 7\%, the crystallinity of the $\mathrm{Eu}^{3+}$-doped $\mathrm{ZnO}-\mathrm{Li}_{3} \mathrm{NbO}_{4}$ is expected to become lower. This phenomenon is mainly caused by structural distortion induced by internal stress. ${ }^{(11)}$

Figures 2(a)-2(f) show the SEM images of $\mathrm{ZnO}-\mathrm{Li}_{3} \mathrm{NbO}_{4}$ phosphors synthesized by the solgel method at different annealing temperatures. The $\mathrm{ZnO}-\mathrm{Li}_{3} \mathrm{NbO}_{4}$ phosphors synthesized at temperatures of $400-700{ }^{\circ} \mathrm{C}$ were mostly irregular and agglomerated, and their surfaces were rough. On the other hand, the $\mathrm{ZnO}-\mathrm{Li}_{3} \mathrm{NbO}_{4}$ phosphors synthesized at temperatures of

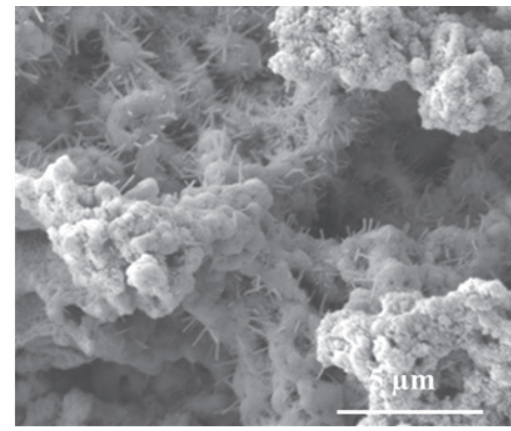

(a)

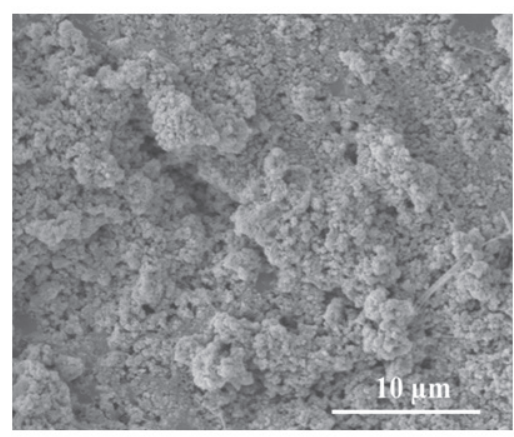

(c)

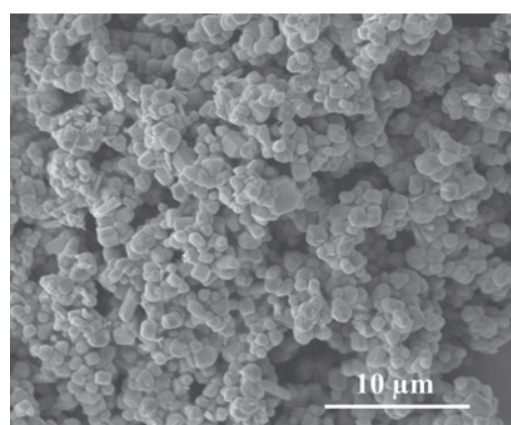

(e)

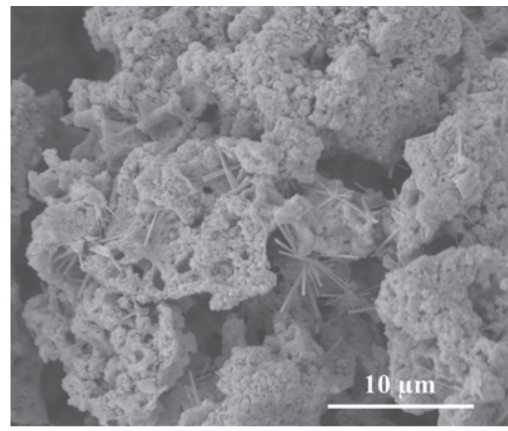

(b)

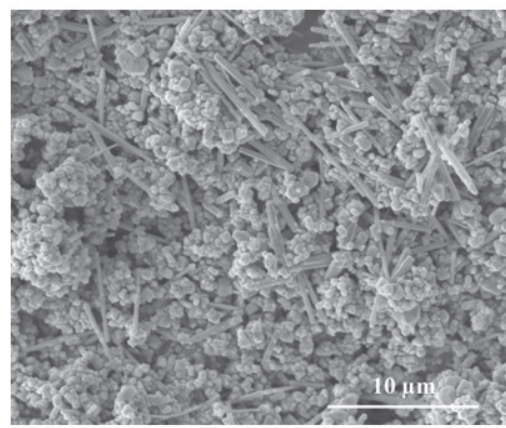

(d)

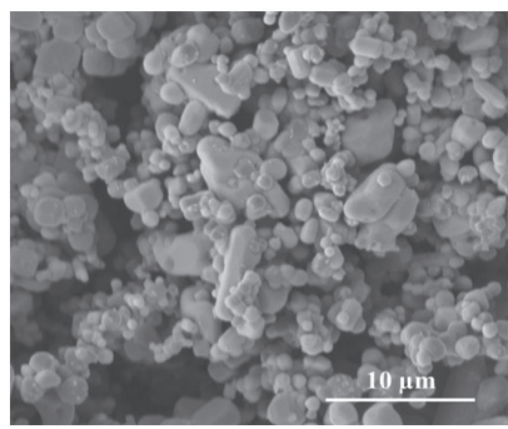

(f)

Fig. 2. SEM images of $\mathrm{ZnO}-\mathrm{Li}_{3} \mathrm{NbO}_{4}$ phosphors synthesized at different annealing temperatures: (a) 400, (b) 500, (c) 600 , (d) 700 , (e) 800 , and (f) $900{ }^{\circ} \mathrm{C}$. 
$800-900{ }^{\circ} \mathrm{C}$ showed a similar particle size of about $500 \mathrm{~nm}$ and appeared spherical. As the temperature increased, the particle size increased. This was because the high temperature promoted the migration of atoms and the growth of pure grains, affecting the shape of the synthesized $\mathrm{ZnO}$ particles forming the films with increasing shape factor. ${ }^{(12)}$ Polygonal $\mathrm{Li}_{3} \mathrm{NbO}_{4}$ particles were formed by assembling grains with one cubic crystalline phase in the ceramic matrix. ${ }^{(13)}$

Figures 3(a)-3(d) show the TEM images of $\mathrm{ZnO}-\mathrm{Li}_{3} \mathrm{NbO}_{4}$ phosphors synthesized at different temperatures. When the annealing temperature increased, the stacking and aggregation of $\mathrm{ZnO}-\mathrm{Li}_{3} \mathrm{NbO}_{4}$ particles occurred. Figure 4(a) shows the high-resolution TEM (HR-TEM) image of $\mathrm{ZnO}-\mathrm{Li}_{3} \mathrm{NbO}_{4}$ at an annealing temperature of $900{ }^{\circ} \mathrm{C}$. From the HR-TEM images, the particle size was calculated to be approximately $10-50 \mathrm{~nm}$. Figures 4 (b) and 4(c) show the

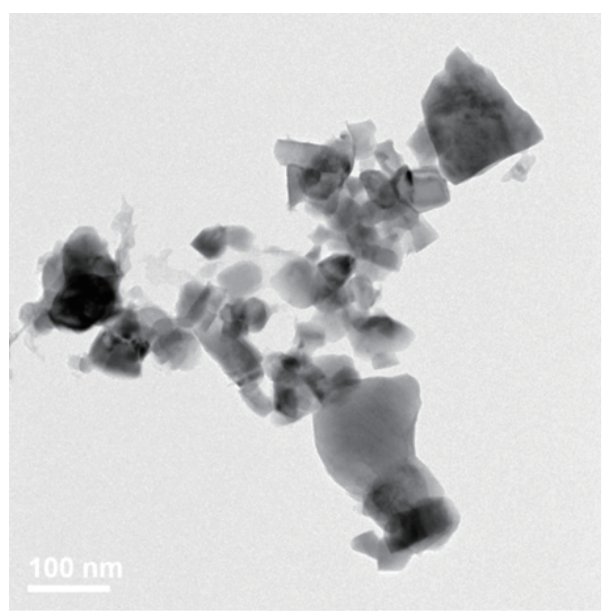

(a)

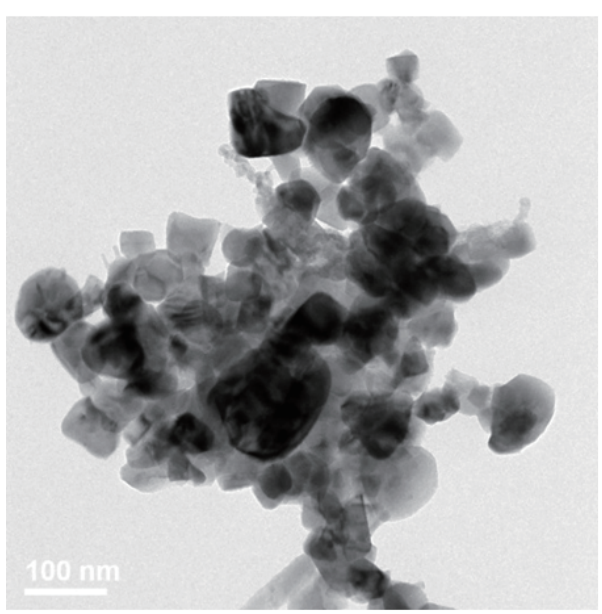

(c)

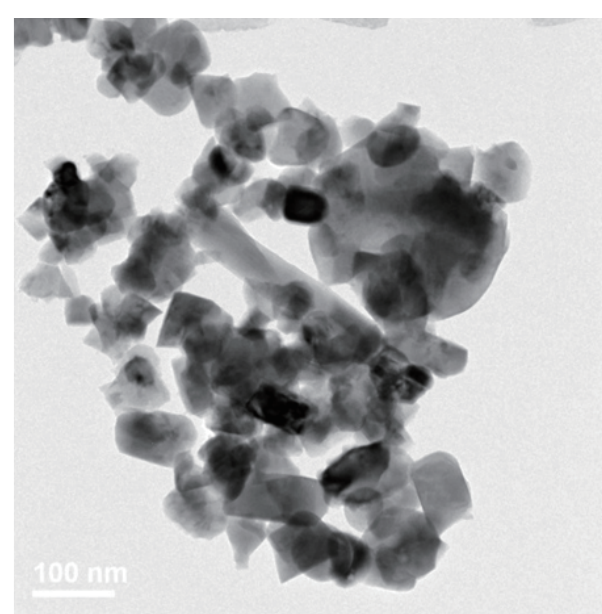

(b)

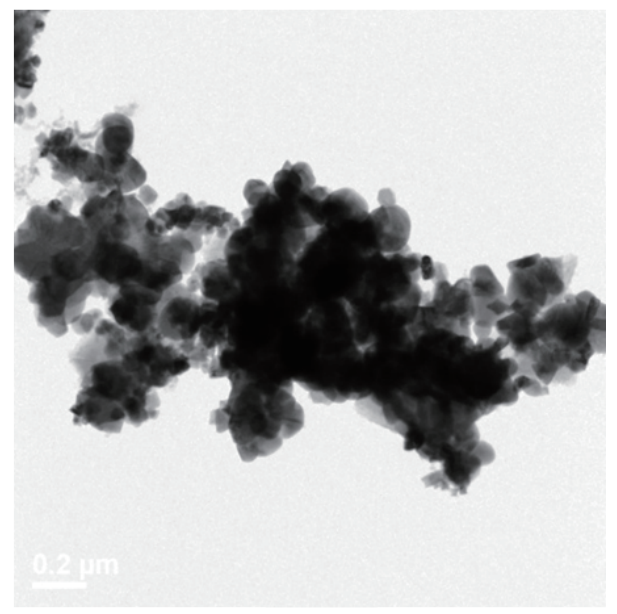

(d)

Fig. 3. TEM images of $\mathrm{ZnO}-\mathrm{Li}_{3} \mathrm{NbO}_{4}$ phosphors synthesized at different temperatures: (a) 600, (b) 700, (c) 800, and (d) $900{ }^{\circ} \mathrm{C}$. 


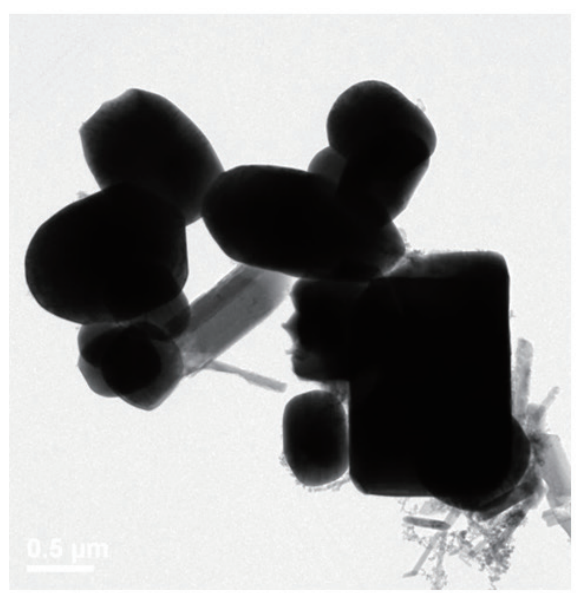

(a)

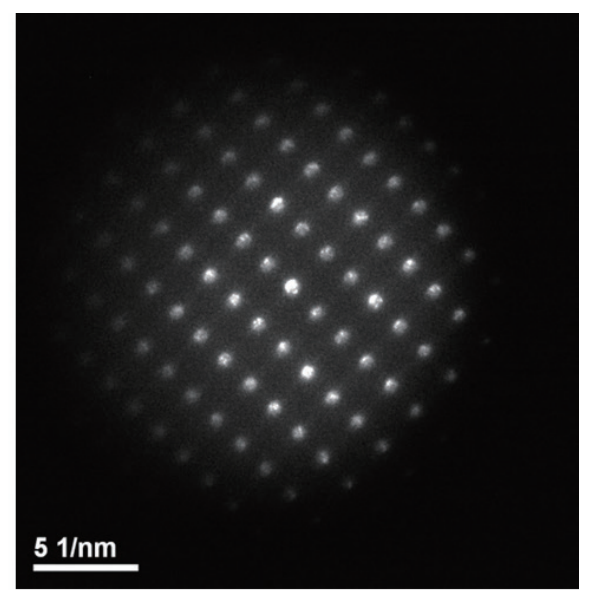

(b)

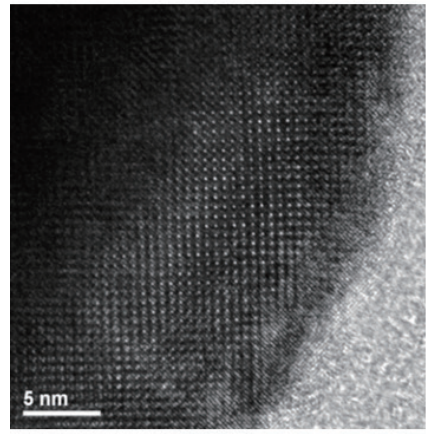

(c)

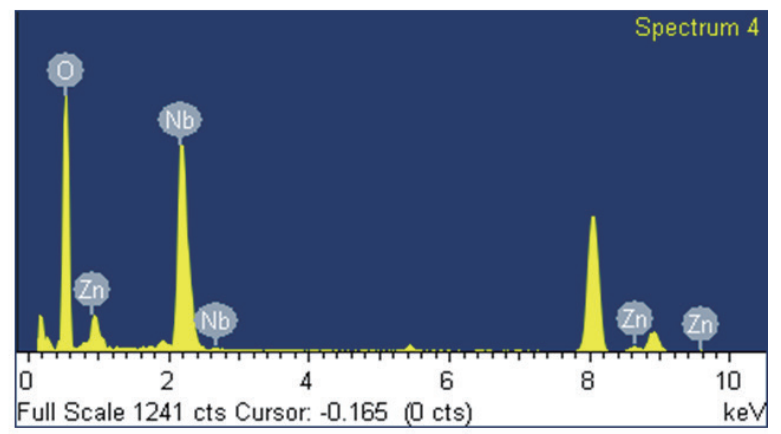

(d)

Fig. 4. (Color online) (a) HR-TEM image of pure $\mathrm{ZnO}-\mathrm{Li}_{3} \mathrm{NbO}_{4}$ precursor powders, (b) SAED pattern of $\mathrm{ZnO}-$ $\mathrm{Li}_{3} \mathrm{NbO}_{4}$ annealed at $900{ }^{\circ} \mathrm{C}$ for $2 \mathrm{~h}$, (c) electron diffraction pattern, and (d) EDS image.

HR-TEM and SAED patterns of $\mathrm{ZnO}-\mathrm{Li}_{3} \mathrm{NbO}_{4}$, respectively. From the images of the lattice arrangement of $\mathrm{ZnO}-\mathrm{Li}_{3} \mathrm{NbO}_{4}$, it can be seen that the ordering of the lattices is accurate, showing a single complete crystal structure. The lattice size was calculated to be about 0.63 nm. Figure 4(d) shows an energy-dispersive X-ray spectroscopy (EDS) image. EDS results showed the composition of $\mathrm{ZnO}-\mathrm{Li}_{3} \mathrm{NbO}_{4}$.

Figure 5 shows the absorption spectra of $\mathrm{ZnO}-\mathrm{Li}_{3} \mathrm{NbO}_{4}$ doped with $5 \mathrm{~mol} \% \mathrm{Eu}^{3+}$ and annealed at $900{ }^{\circ} \mathrm{C}$ for $2 \mathrm{~h}$. The high absorption spectral peak of $\mathrm{ZnO}-\mathrm{Li}_{3} \mathrm{NbO}_{4}: \mathrm{Eu}^{3+}$ was located between 300 and $400 \mathrm{~nm}$. The absorption spectral peaks at 466 and $538 \mathrm{~nm}$ corresponded to ${ }^{7} \mathrm{~F}_{0} \rightarrow{ }^{5} \mathrm{D}_{2}$ and ${ }^{7} \mathrm{~F}_{0} \rightarrow{ }^{5} \mathrm{D}_{1}$, respectively. This behavior was attributed to the transition from the ${ }^{7} \mathrm{~F}_{0}$ ground state to the charge transfer state (CTS). ${ }^{(10)}$ The absorption coefficient can be obtained on the basis of the relationship between $(a h v)^{2}$ and the photon energy $^{(10)}$ as

$$
a=\frac{C\left(h v-E_{g}\right)^{1 / 2}}{h v}
$$




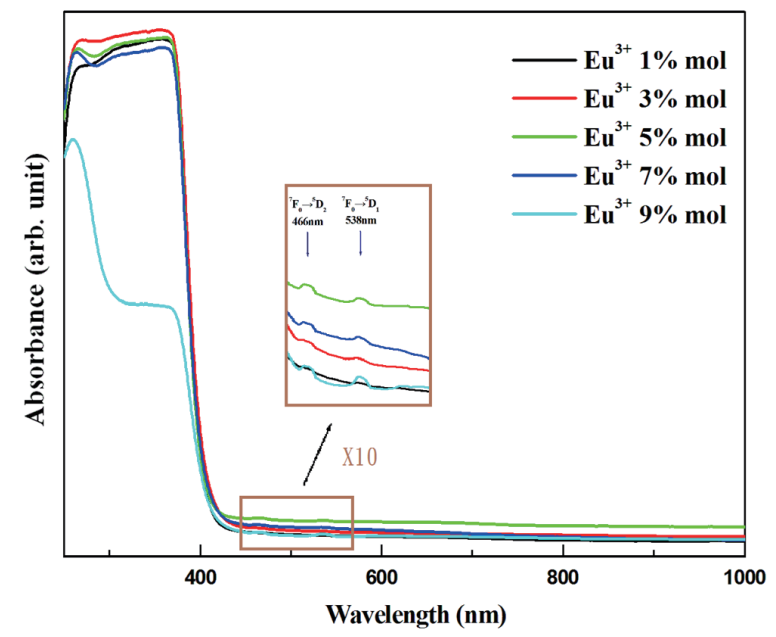

Fig. 5. (Color online) Absorption spectra of $\mathrm{ZnO}-\mathrm{Li}_{3} \mathrm{NbO}_{4}: x \mathrm{Eu}^{3+}(x=1,3,5,7$, and 9\%).

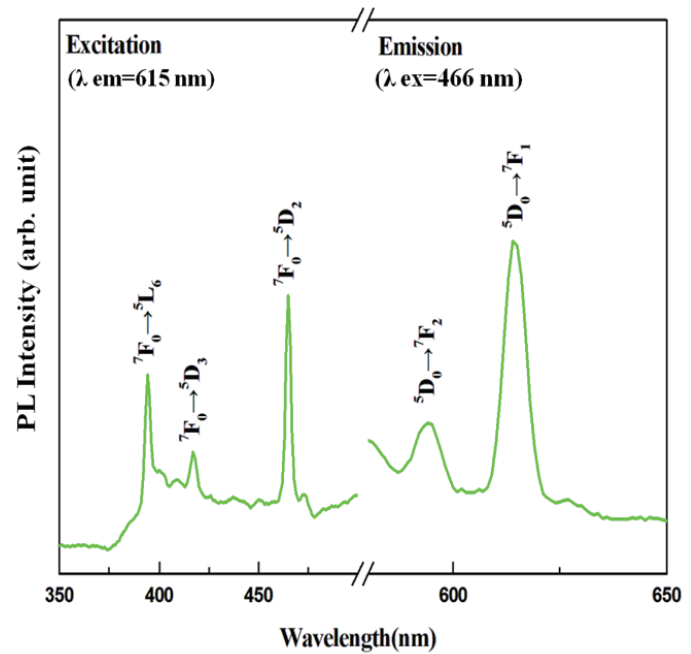

(a)

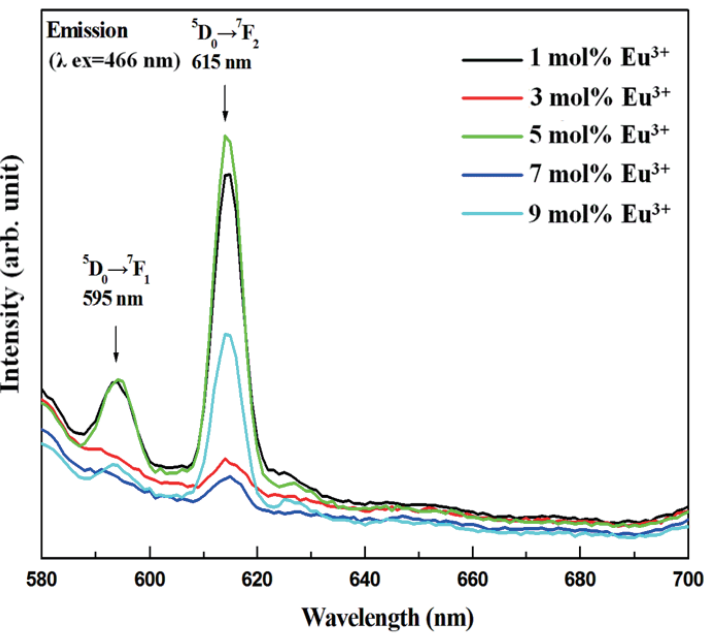

(b)

Fig. 6. (Color online) (a) Eu-doped $\mathrm{ZnO}-\mathrm{Li}_{3} \mathrm{NbO}_{4}$ concentration-dependent $\mathrm{PL}$ intensity ratio of ${ }^{5} \mathrm{D}_{0}{ }^{-}{ }^{7} \mathrm{~F}_{1}(\mathrm{R}){ }^{5} \mathrm{D}_{0}$ ${ }^{7} \mathrm{~F}_{2}(\mathrm{O})$. (b) Emission spectra of $\mathrm{ZnO}-\mathrm{Li}_{3} \mathrm{NbO}_{4}: x \mathrm{Eu}^{3+}(x=1,3,5,7$, and $9 \%)$.

where $a$ is the absorption coefficient, $C$ is a constant, $h v$ is the photon energy, and $E_{g}$ is the energy band gap. The $E_{g}$ of $\mathrm{Eu}^{3+}$-doped $\mathrm{ZnO}-\mathrm{Li}_{3} \mathrm{NbO}_{4}$ was $3.13-3.24 \mathrm{eV}$. This result was similar to previously reported results. ${ }^{(11,14)}$

Figure 6(a) shows the PL intensity-wavelength image of $\mathrm{Eu}^{3+}$ ions, which shows an excitation band at $\lambda_{e x}=466 \mathrm{~nm}\left({ }^{7} \mathrm{~F}_{0} \rightarrow{ }^{5} \mathrm{D}_{2}\right)$. The excitation and emission intensities of the $4 \mathrm{f}$ inner layer of the orbital transition of $\mathrm{Eu}^{3+}$-doped $\mathrm{ZnO}-\mathrm{Li}_{3} \mathrm{NbO}_{4}$ predominantly showed the characteristic absorption peaks. ${ }^{(1)}$ In the image, the first emission peak and the highest emission peak, which is classified as orange light, appear at $\lambda_{e m}=595 \mathrm{~nm}\left({ }^{5} \mathrm{D}_{0} \rightarrow{ }^{7} \mathrm{~F}_{1}\right)$ and $\lambda_{e m}=615 \mathrm{~nm}\left({ }^{5} \mathrm{D}_{0} \rightarrow{ }^{7} \mathrm{~F}_{2}\right)$, respectively. 


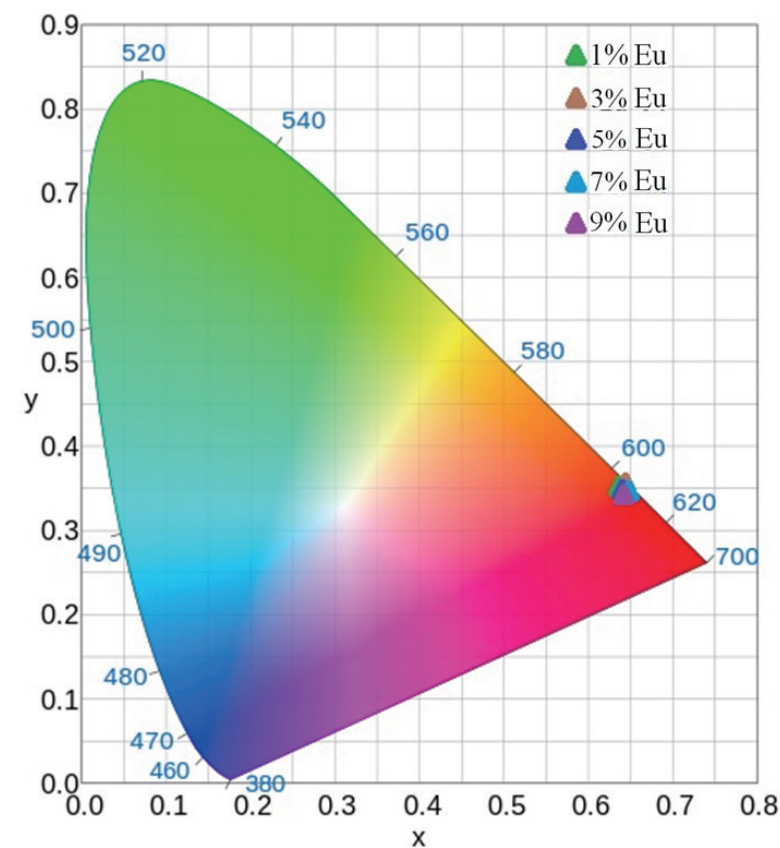

Fig. 7. (Color online) CIE color coordinate diagram of $\mathrm{ZnO}-\mathrm{Li}_{3} \mathrm{NbO}_{4}: x \mathrm{Eu}^{3+}(x=1,3,5,7$, and 9\%).

Figure 6(b) shows that the luminous intensity was observed to be the highest at $5 \% \mathrm{Eu}^{3+}$ and began to decrease at $7 \% \mathrm{Eu}^{3+}$. This was caused by the transfer of energy, during which the activator ion concentration saturated and reached its maximum simultaneously. ${ }^{(1)}$ This revealed that the concentration of crystal defects attributed to the luminous intensity decreased during the transfer of energy. The concentration-dependent intensity ratios of ${ }^{5} \mathrm{D}_{0} \rightarrow{ }^{7} \mathrm{~F}_{2} /{ }^{5} \mathrm{D}_{0} \rightarrow{ }^{7} \mathrm{~F}_{1}(\mathrm{R} /$ O) for $1,3,5,7$, and $9 \% \mathrm{Eu}^{3+}$-doped $\mathrm{ZnO}-\mathrm{Li}_{3} \mathrm{NbO}_{4}$ were 2.04, 0.92, 2.21, 0.94, and 2.12, respectively. When the concentration of the $\mathrm{Eu}^{3+}$ dopant was increased to $5 \%$ to form $\mathrm{Eu}^{3+}$ doped $\mathrm{ZnO}-\mathrm{Li}_{3} \mathrm{NbO}_{4}$, the intensity ratio $(\mathrm{R} / \mathrm{O})$ became maximum.

Figure 7 shows CIE color coordinates of $\mathrm{ZnO}-\mathrm{Li}_{3} \mathrm{NbO}_{4}$ with 1 to $9 \mathrm{~mol} \% \mathrm{Eu}^{3+}$ doping concentrations. The CIE chromaticity coordinates show the shifted area at about $x=0.65$ and $y=0.35$, which was located at an orange-red light area. Such coordinates were not clearly affected by the different $\mathrm{Eu}^{3+}$ doping concentrations.

\section{Conclusions}

In this study, $\mathrm{Eu}^{3+}$-doped $\mathrm{ZnO}-\mathrm{Li}_{3} \mathrm{NbO}_{4}$ was successfully synthesized. XRD analysis showed that the $\mathrm{ZnO}-\mathrm{Li}_{3} \mathrm{NbO}_{4}$ structure gradually formed at $400{ }^{\circ} \mathrm{C}$ and the highest crystallinity was obtained at $900{ }^{\circ} \mathrm{C}$. When $5 \% \mathrm{Eu}^{3+}$ was doped into the $\mathrm{ZnO}-\mathrm{Li}_{3} \mathrm{NbO}_{4}$ structure, the highest emission intensity of ${ }^{5} \mathrm{D}_{0} \rightarrow{ }^{7} \mathrm{~F}_{1}(466 \mathrm{~nm})$ was obtained. When the CIE color coordinates of $\mathrm{Eu}^{3+}: \mathrm{ZnO}-\mathrm{Li}_{3} \mathrm{NbO}_{4}$ (about $x=0.65$ and $y=0.35$ ) were obtained, an orange-red sample was similarly observed at $5 \% \mathrm{Eu}^{3+}$. These results will be useful in the field of biological and optical detection. 


\section{Acknowledgments}

This study was financially supported by the Ministry of Science and Technology (MOST), Taiwan, under Grant MOST 106-2221-E-151-026-MY3 and MOST 108CP01.

\section{References}

1 M. Ferrol and S. Lecocq: Eur. J. Solid State Inorg. Chem. 35 (1998) 10. https://doi.org/10.1016/S09924361(99)80011-3

2 V. A. Morozov, A. V. Arakcheeva, V. V. Konovalova, P. Pattison, G. Chapuis, O. I. Lebedev, V. V. Fomichev, and G. V. Tendeloo: J. Solid State Chem. 183 (2010) 2. https://doi.org/10.1016/j.jssc.2009.12.008

3 N. M. Fariña, F. M. Guzón, M. L. Peña, and A. G. Cantalapiedra: J. Mater. Sci.-Mater. Med. 19 (2008) 4. https://doi.org/10.1007/s10856-008-3400-y

4 D. Bernardeschi, Y. Nguyen, I. Mosnier, M. Smail, E. Ferrary, and O. Sterkers: Eur. Arch. Otorhinolaryngol. 271 (2014) 1. https://doi.org/10.1007/s00405-013-2393-4

5 K. B. Kim, K. W. Koo, T. Y. Cho, and H. G. Chun: Mater. Chem. Phys. 80 (2003) 3. https://doi.org/10.1016/ S0254-0584(03)00110-X

6 Y. Wang, T. Endo, E. Xie, D. He, and B. Liu: Microelectron. J. 35 (2004) 4. https://doi.org/10.1016/S00262692(03)00245-3

7 R. S. Ningthoujam, N. S. Gajbhiye, A. Ahmed, S. S. Umre, and S. J. Sharma: J. Nanosci. Nanotechnol. 8 (2008) 6. https://doi.org/10.1166/jnn.2008.152

8 J. Wang, H. Hong, X. Kong, H. Peng, B. Sun, B. Chen, J. Zhang, W. Xu, and H. Xia: J. Appl. Phys. 93 (2003) 3. https://doi.org/10.1063/1.1536726

9 Z. Wang, D. Yuan, D. Xu, M. Lv, X. Cheng, L. Pan, and X. Shi: J. Cryst. Growth 255 (2003) 3. https://doi. org/10.1016/S0022-0248(03)01269-7

10 Z. W. Chiu, Y. J. Hsiao, T. H. Fang, and L. W. Ji: J. Sol-Gel Sci. Technol. 69 (2014) 2. https://doi.org/10.1007/ s10971-013-3215-2

11 M. H. Huang, T. H. Fang, M. H. Lin, and C. W. Chang: Mater. Res. Express 5 (2018) 4. https://doi.org/00000002-7032-3193

12 L. Znaidi, T. Chauveau, A. Tallaire, F. Liu, M. Rahmani, V. Bockelee, D. Vrel, and P. Doppelt: Thin Solid Films 617 (2016) 156. https://doi.org/10.1016/j.tsf.2015.12.031

13 Y. J. Hsiao, T. H. Fang, S. J. Lin, J. M. Shieh, and L. W. Ji: J. Lumin. 130 (2010) 10. https://doi.org/10.1016/ j.jlumin.2010.04.023

14 A. Boonchun and W. R. L. Lambrecht: Phys. Rev. B 81 (2010) 079904. https://doi.org/10.1103/ PhysRevB.81.235214

\section{About the Authors}

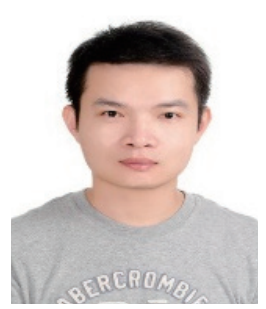

Meng-Hsi Huang received his B.S. degree from National Pingtung University of Science and Technology, Taiwan, in 2007 and his M.S. degree from National Kaohsiung University of Applied Sciences, Taiwan, in 2014. Since 2016, he has been a Ph.D. student at National Kaohsiung University of Science and Technology, Taiwan. His research interests are in nanotechnology and fluorescent materials. (1105403105@nkust.edu.tw) 


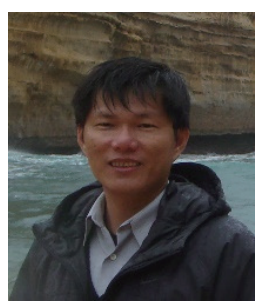

Te-Hua Fang received his B.S. degree from National Taiwan Institute of Technology, Taiwan, in 1992 and his M.S. and Ph.D. degrees from National Cheng Kung University, Taiwan, in 1994 and 2000, respectively. From 2001 to 2007, he was an assistant professor at Southern Taiwan University of Technology and National Formosa University, Taiwan. Since 2007, he has been a full professor at National Formosa University and National Kaohsiung University of Science and Technology. He is an IET Fellow. His research interests are in molecular dynamics, nanotechnology, materials, mechanics, and scanning probe microscopy. (fang.tehua@msa.hinet.net)

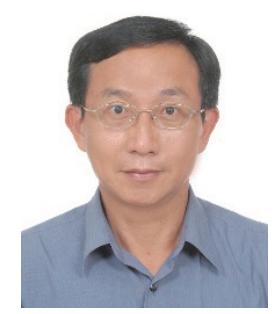

Ming-Hong Lin received his B.S. degree from National Taiwan Institute of Technology, Taiwan, in 1983, his M.S. degree from National Cheng Kung University, Taiwan, in 1985, and his Ph.D. degree from National Sun YatSen University, Taiwan, in 1998. From 1996 to 2004, he was an assistant professor at National Kaohsiung University of Science and Technology. Since 2004, he has been a full professor at National Kaohsiung University of Science and Technology. His research interests are in mechanical materials, nanotechnology, ceramic materials, heat treatment, and surface modification. (mhlin@nkust.edu.tw)

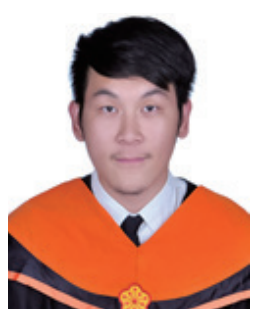

Chia-Wei Chang received his B.S. and M.S. degrees from National Kaohsiung University of Applied Sciences, Taiwan, in 2013 and 2015, respectively. His research interest is in fluorescent materials. (allegra5202005@yahoo.com.tw)

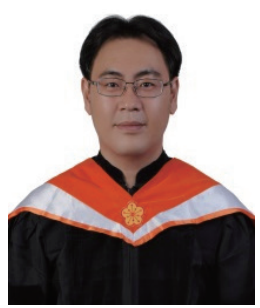

Yu-Cheng Fan received his B.S. degree from National Kaohsiung University of Applied Sciences, Taiwan, in 2007, his M.S. degree from National Formosa University, Taiwan, in 2009, and his Ph.D. degree from National Kaohsiung University of Applied Sciences, Taiwan, in 2017. Since 2018, he has been an assistant researcher at National Kaohsiung University of Science and Technology, Taiwan. (yucheng.fan@nkust.edu.tw) 